\title{
TOWARD A MONITORING
}

AND FORECASTING

SYSTEM FOR ATMOSPHERIC

COMPOSITION

The GEMS Project

by A. Hollingsworth, R. J. Engelen, C. Textor, A. Benedetti,

O. Boucher, F. Chevallier, A. Dethof, H. Elbern, H. Eskes,

J. Flemming, C. Granier, J. W. Kaiser, J.-J. Morcrette,

P. Rayner, V.-H. Peuch, L. Rouil, M. G. Schultz,

A. J. SimMONS, AND THE GEMS CONSORTIUM

The European GEMS project is building a comprehensive monitoring and forecasting system for atmospheric composition on both global and regional scales.

W

ith the advance of satellite remote sensing of the Earth's atmosphere, a clearer picture is starting to emerge of how natural and anthropogenic emissions are influencing the composition of the atmosphere on a global scale. While climate and pollution problems, such as the Antarctic ozone hole (Farman et al. 1985), increase in atmospheric $\mathrm{CO}_{2}$ (Keeling et al. 1976) and pollution around cities, have often been first detected by ground-based measurements, satellite observations have the capability of showing the large-scale patterns. Good examples are the geostationary images of desert dust plumes stretching all the way from the Sahara to South America (see information online at http://oiswww.eumetsat.org/WEBOPS/iotm/ iotm/20040306_dust/20040306_dust.html), observations of the Antarctic ozone hole by various satellite sensors (e.g., Www.nasa.gov/vision/earth/environment/ozone resource. page.html), and the recent global views of tropospheric $\mathrm{NO}_{2}$ pollution as measured by the Global Ozone Monitoring Experiment (GOME), the Scanning Imaging Absorption Spectrometer for Atmospheric Cartography (SCIAMACHY), and the Ozone Monitoring Instrument (OMI; information at www.knmi.nl/omi/publ-n/metingen/no2/metingen no2 nrt. html). These examples clearly show 
the large potential of these observations for helping to provide a better understanding of the Earth's atmospheric composition and changes therein.

Growing awareness of the adverse effects of human interaction with the composition of the Earth's atmosphere and the increasing availability of satellite observations has recently led to the publication of several key reports describing the need for global data assimilation systems that can optimally combine the diverse observational data streams to monitor the changes in atmospheric composition. The Global Carbon Project (GCP) stated in its 2003 report that we need to "develop and implement methods for assimilating atmospheric, ocean and terrestrial data into carbon-climate-human system models, with particular emphasis on the application of multiple constraints to the problem of determining patterns and variability in the carbon cycle" (Global Carbon Project 2003). A year later, a report from Integrated Global Observing Strategy (IGOS)/Integrated Global Atmospheric Chemistry Observations (IGACO) group asked for "a comprehensive data modelling system capable of combining the data for the chemical species, aerosols and ancillary parameters into a comprehensive global picture" (IGACO 2004). At the same time there is a strong request from policy makers for global atmospheric composition monitoring systems to support decision making related to international protocols and conventions, such as the Kyoto Protocol, the Montreal Protocol, the Convention on Long-Range Transboundary Air Pollution (CLTRAP), and the United Nations (UN) Framework Convention on Climate Change (FCCC).

On the observational side, both the Global Climate Observing System (GCOS) and the Committee on Earth Observation Satellites (CEOS) outlined the requirements for global observing systems to monitor climate change (GCOS 2004, 2006; CEOS 2006). A wealth of spaceborne data has become available from the current American Earth Observing System (EOS) and European Environmental Satellite (Envisat) as well as from smaller platforms. The new generation of operational satellite systems, such as the recently launched first platform of the European Meteorological Operation (MeTop) series and the forthcoming American National Polar-Orbiting Operational Environmental Satellite System (NPOESS) series, will continue to provide key observations for monitoring the atmosphere, although to a lesser extent. Also, the amount of high-quality in situ observations continues to increase, providing a wealth of information on the local and regional scales.

This increased availability of atmospheric composition data creates the opportunity to build systems that can combine these observations with state-ofthe-art models to address important science and policy-making questions, such as the uncertainty in global carbon fluxes (e.g., Baker et al. 2006), the need for improved air quality forecasts (e.g., Elbern et al. 1997), and the need for better monitoring and forecasting of long-range transport of air pollution and aerosol (HTAP 2007).

Many research groups have used various data assimilation techniques to study either individual components of the atmospheric composition distribution or regional problems (e.g., Chai et al. 2006; Generoso et al. 2007; Fonteyn et al. 2000; Stajner et al. 2001; Dethof and Holm 2004; Geer et al. 2006; Lahoz et al. 2007). However, there has not been any effort to build a fully integrated system combining the various observational data sources to obtain a complete and consistent view of the atmospheric composition. Such an integrated system could make use of the interactions between the various components, for example, the chemical production and loss of $\mathrm{CO}_{2}$ and $\mathrm{CH}_{4}$, which are relevant to greenhouse gas monitoring, or the generation of sulfate aerosol through the oxidation of sulfur dioxide. On the other hand, there is vast experi-

UPMC, Paris, France; PEUCH-Centre National de Recherches Météorologiques, Météo-France, and CNRS, Paris, France; RouIL-INERIS, Paris, France; SCHULTZ-Forschungs Zentrum Jülich, Jülich, Germany

*Deceased CORRESPONDING AUTHOR: Richard Engelen, ECMWF, Shinfield Park, Reading RG2 9AX, United Kingdom

E-mail: richard.engelen@ecmwf.int

DOI:10.1175/2008BAMS2355.1

In final form 7 February 2008

O2008 American Meteorological Society 
ence with global data assimilation in the various numerical weather prediction (NWP) institutes around the world. For many years techniques have been developed and improved to optimally combine atmospheric model forecasts with the enormous amount of meteorological observations to estimate the meteorological state of the atmosphere. It is therefore very attractive to combine this experience with that of the diverse research groups engaged in atmospheric composition modeling to build an integrated monitoring system. So far, only a few initiatives have been started. In Europe, the European Commission (EC) has been funding the Global and Regional Earth-System Monitoring Using Satellite and In situ Data (GEMS; information online at http://gems.ecmwf.int/) project since March 2005 to build a global assimilation/forecasting system for greenhouse gases (GHG), global reactive gases (GRG), and aerosol (AER), and to implement a linked program of regional air quality (RAQ) prediction using an ensemble of forecasting systems. In the United States, funding has been put in place to build an assimilation system for air quality, aerosol, and the carbon cycle at the National Aeronautics and Space Administration (NASA)/Global Modeling and Assimilation Office (GMAO; online at http://gmao. gsfc.nasa.gov). Also, the National Oceanic and Atmospheric Administration (NOAA)/National Weather Service (NWS) collaborates with the U.S. Environmental Protection Agency (EPA) to build a data assimilation system that is used for operational air quality forecasting. Finally, the Infusing Satellite Data into Environmental Applications (IDEA) project combines efforts from NASA, NOAA, and EPA to improve air quality assessment, management, and prediction by infusing satellite measurements into analyses for public benefit (Al-Saadi et al. 2005).

This paper describes the objectives, structure, and progress of the European GEMS project. GEMS is funded within the Global Monitoring for Environment and Security (GMES; www.gmes.info) framework, initiated by the EC and the European Space Agency (ESA), which aims to make environmental information more readily accessible to both service providers and end users. GMES assembles the information acquired in a reliable, valid, and compatible manner and makes it available for user-friendly exploitation. The GMES services will be used by environmental agencies; local, regional, and national authorities; and civil protection organizations, among others. Within this GMES framework, the GEMS project aims to build the atmospheric composition component, as outlined in the next section.
GEMS OBJECTIVES. The GEMS project is unique, because for the first time it combines the experience from a large number of research communities in Europe to develop a comprehensive atmospheric composition monitoring and forecasting system. Leading research groups in the areas of greenhouse gases, reactive gases, aerosol, and regional air quality are merging their own expertise with the data assimilation experience that is available at the European Centre for Medium-Range Weather Forecasts (ECMWF). Table 1 lists the 32 institutes that participate in GEMS and the subprojects of which they are a part. The subprojects will be described in more detail below. The table immediately shows the diverse experience among the partner institutes, which can be divided into the following four categories:

- Eighteen research institutes in seven countries provide expertise in satellite and in situ observations for assessing/validating models, developing models and assimilation systems of tropospheric and stratospheric chemistry and aerosol, and inversion methods to estimate sources, sinks, and transport.

- Ten regional modeling centers operate in nine countries, most with operational responsibilities for national or regional air quality forecasts.

- Two environmental protection agencies are active.

- Two European bodies participate-ECMWF, with extensive experience in exploiting satellite and in situ data to produce numerical weather forecasts, and the Institute for Environment and Sustainability of the Joint Research Centre of the European Commission, with extensive experience covering the entire environmental sciences with particular competence in the field of Earth observation and remote sensing.

The GEMS project uses the combined expertise to develop a preoperational pilot system with a nearreal-time data assimilation and forecast capability for aerosols, greenhouse gases, and reactive gases. The new system will be an extension of current data assimilation and forecast capabilities for numerical weather prediction that are in place at ECMWF. It can be used to monitor the composition of the atmosphere, infer estimates of surface fluxes, and produce global, short-range, and medium-range air chemistry forecasts, combining remotely sensed and in situ data with state-of-the-art modeling. Deliverables include synoptic analyses and forecasts of three-dimensional 
TABLE I. Members of the GEMS consortium.

\begin{tabular}{|c|c|c|c|}
\hline Partner name & Country & Web site & Subprojects \\
\hline Institut d'Aéronomie Spatiale de Belgique & Belgium & www.aeronomie.be & GRG \\
\hline $\begin{array}{l}\text { Koninklijk Meteorologisch Instituut, Institut } \\
\text { Royal Meteorologique }\end{array}$ & Belgium & www.meteo.be & AER \\
\hline Czech Hydrometeorological Institute & Czech Republic & www.chmi.cz/indexe.html & RAQ \\
\hline Danish Meteorological Institute & Denmark & www.dmi.dk/eng/index/forecasts.htm & GRG, RAQ, VAL \\
\hline Finnish Meteorological Institute & Finland & www.fmi.fi/en/ & GRG, AER, RAQ \\
\hline $\begin{array}{l}\text { Institut National de l'Environnement Industriel } \\
\text { et des Risques }\end{array}$ & France & www.ineris.fr & RAQ \\
\hline $\begin{array}{l}\text { Laboratoire d'Aérologie, Centre National de la } \\
\text { Recherche Scientifique (CNRS) }\end{array}$ & France & www.aero.obs-mip.fr & GRG, RAQ \\
\hline $\begin{array}{l}\text { Laboratoire de Météorologie Dynamique, } \\
\text { (CNRS) }\end{array}$ & France & www.Imd.jussieu.fr & GHG, RAQ \\
\hline $\begin{array}{l}\text { Laboratoire des Sciences du Climat et de } \\
\text { l'Environnement, Commissariat à l'Énergie } \\
\text { Atomique (CEA) }\end{array}$ & France & www.lsce.cea.fr & GHG, AER \\
\hline Laboratoire d'Optique Atmosphérique, (CNRS) & France & www-loa.univ-lillel.fr & AER \\
\hline $\begin{array}{l}\text { Laboratoire Interuniversitaire des Systèmes } \\
\text { Atmosphériques, (CNRS) }\end{array}$ & France & www.lisa.univ-paris $12 . f r$ & RAQ \\
\hline $\begin{array}{l}\text { Météo-France, Centre National de Recherches } \\
\text { Météorologiques }\end{array}$ & France & www.cnrm.meteo.fr & GRG, RAQ \\
\hline $\begin{array}{l}\text { Service d'Aeronomie, Universite Pierre et Marie } \\
\text { Curie }\end{array}$ & France & www.aero.jussieu.fr & GRG, AER, RAQ \\
\hline Deutscher Wetterdienst & Germany & $\begin{array}{l}\text { www.dwd.de/en/FundE/Observator/ } \\
\text { MOHP/MOHP.htm }\end{array}$ & GRG, AER \\
\hline Forschungszentrum, Jülich & Germany & www.fz-juelich.de/portal & GRG \\
\hline Max Planck Institut für Meteorologie & Germany & www.mpimet.mpg.de & GRG, AER, RAQ \\
\hline Max-Planck-Institute for Biogeochemistry & Germany & www.bgc-jena.mpg.de & GHG, VAL \\
\hline $\begin{array}{l}\text { Rheinisches Institut für Umweltforschung } \\
\text { Universität Köln }\end{array}$ & Germany & www.eurad.uni-koeln.de & RAQ \\
\hline University of Bremen & Germany & www.iup.uni-bremen.de/sciamachy/ & GRG \\
\hline National and Kapodistrian University of Athens & Greece & www.uoa.gr & GRG, RAQ \\
\hline Irish Environmental Protection Agency & Ireland & www.epa.ie & RAQ \\
\hline National University of Ireland, Galway & Ireland & http://macehead.nuigalway.ie & $A E R, V A L$ \\
\hline Trinity College Dublin & Ireland & www.tcd.ie & RAQ \\
\hline ARPA Emilia-Romagna & Italy & www.arpa.emr.it & RAQ \\
\hline $\begin{array}{l}\text { Instituto di Scienze dell'Atmosfera e del Clima } \\
\text { Consiglio Nazionale delle Ricerche }\end{array}$ & Italy & www.isac.cnr.it & RAQ \\
\hline $\begin{array}{l}\text { European Centre for Medium-Range Weather } \\
\text { Forecasts }\end{array}$ & International & www.ecmwf.int & $\begin{array}{l}\text { PRO, GHG, GRG, } \\
\text { AER }\end{array}$ \\
\hline $\begin{array}{l}\text { Joint Research Centre, Institute for } \\
\text { Environment and Sustainability }\end{array}$ & International & http://ies.jrc.cec.eu.int & GHG \\
\hline Royal Netherlands Meteorological Institute & Netherlands & $\begin{array}{l}\text { www.knmi.nl/research/ Atmospher- } \\
\text { ic_composition/ }\end{array}$ & GRG, RAQ VAL \\
\hline Meteorologisk Institutt & Norway & met.no & RAQ \\
\hline Polish Institute of Environmental Protection & Poland & www.ios.edu.pl/eng/welcome.html & RAQ \\
\hline $\begin{array}{l}\text { Imperial College of Science, Technology and } \\
\text { Medicine }\end{array}$ & United Kingdom & www.ic.ac.uk & RAQ \\
\hline Met Office & United Kingdom & www.metoffice.gov.uk/research_top & GHG, AER, RAQ \\
\hline
\end{tabular}


global distributions of key atmospheric trace constituents, including greenhouse gases $\left(\mathrm{CO}_{2}\right.$ and $\left.\mathrm{CH}_{4}\right)$, reactive gases $\left(\mathrm{O}_{3}, \mathrm{NO}_{\mathrm{x}}\right.$, $\mathrm{SO}_{2}, \mathrm{CO}$, and $\mathrm{HCHO}$ ), and aerosols (dust, sea salt, organic matter, black carbon, sulfate, and stratospheric aerosol).

The global assimilation/ forecast system also provides initial and boundary conditions for the regional air quality ("chemical weather") forecast systems, which are run in ensem-

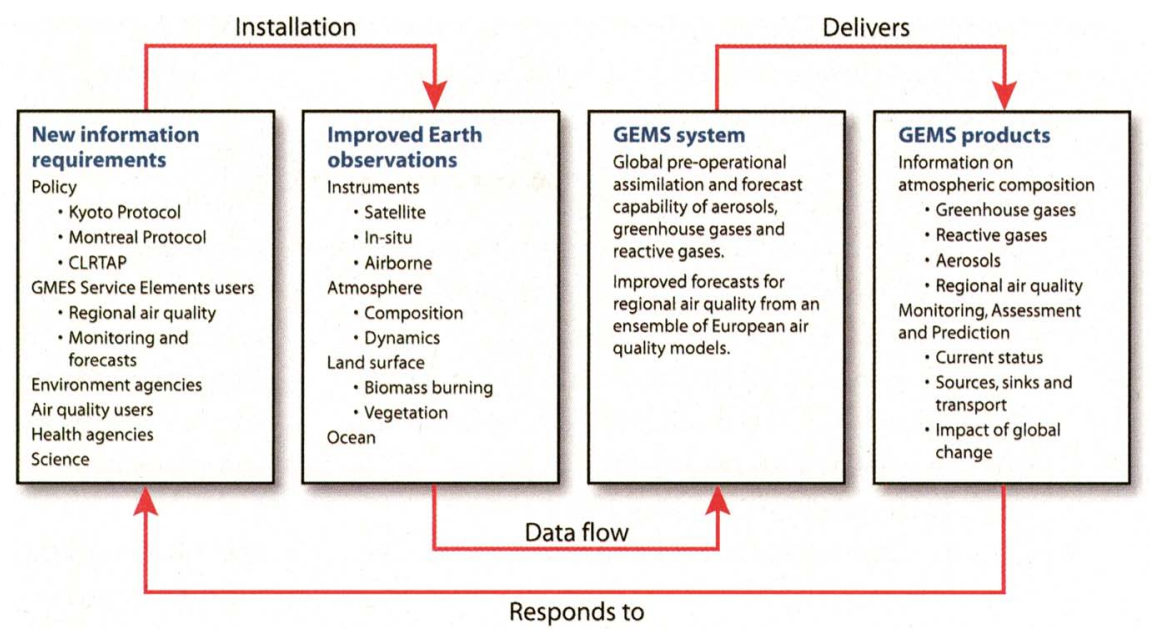

FIG. I. Schematic illustrating the objectives and products of the GEMS project.

ble mode on a common

European domain to provide an uncertainty range, together with the most likely forecast.

At the end of the project, GEMS will have a preoperational system that has the capability to be transformed into a fully operational system. The system can then be run in near-real time or in lagged mode. This will depend on user requirements and on near-real-time observational data availability, which is not necessarily guaranteed because many retrieval products are still in research mode.

For the Envisat-EOS era (2003-07) GEMS will provide a retrospective analysis of various remotely sensed data on atmospheric composition as validation material for the project itself and as a service to the wider science community on which the project relies.

The project is also developing state-of-the-art variational estimates of the sources/sinks of the greenhouse gases, plus intercontinental transports of many trace gases and aerosols. These estimates, based initially on the retrospective analyses, and later on operational analyses, are designed to support the science underlying policy makers' key information requirements relating to the Kyoto and Montreal Protocols and to the UN Convention on Long-Range Trans-Boundary Air Pollution. A schematic representation of the components and products of GEMS is shown in Fig. 1.

THE STRATEGY FOR DEVELOPMENT AND VALIDATION OF A GEMS PREOPERATIONAL SYSTEM. Figure 2 illustrates the main steps of the GEMS strategy to build its integrated monitoring and forecasting system. GEMS comprises four main elements: GHG, GRG, AER, and RAQ.

Research systems for the assimilation of reactive gases and aerosol have been developed in recent years, but none has the comprehensive use of satellite data, the comprehensive validation mechanisms, and the high spatial resolution of the GEMS system. A primary goal is to create an architecture allowing for scientific interactions between these elements in order to develop a fully integrated treatment of all aspects of atmospheric composition and dynamics when it becomes preoperational in the first half of 2009. Full use will be made of the existing infrastructure provided by the World Meteorological Organization's (WMO's) World Weather Watch and European resources in information technology.

The four main elements of GEMS described above are supported by two additional activities. The production element (PRO) implements the new GEMS components into the assimilation system of ECMWF's Integrated Forecasting System (IFS). PRO is also responsible for the data acquisition, data handling, data bias correction, interface with air quality models, and provision of output fields to the outside user community. In addition, the validation element (VAL) ensures unified validation of the integrated system in a concerted effort in the last year of the project when the integrated system will have been created.

As illustrated in Fig. 2, the GEMS strategy is based on a stepwise approach for the global and regional elements, as follows:

Step 1:

- Build and validate three separate global assimilation systems for greenhouse gases, reactive gases, and aerosol. 
- Produce three different global reanalyses for greenhouse gases, reactive gases, and aerosols.

- Make global reanalyses available for validation by all partners.

- Set up interfaces for an ensemble of European regional air quality modeling groups to connect to the GEMS archives to obtain meteorological and chemical boundary conditions.

- Perform a model intercomparison of European regional air quality models using information from the global systems.

- Provide feedback to data providers.

- Acquire observational data and build a Web site.

Step 2:

- Merge the three global assimilation systems into a unified system.

- Perform an extensive model intercomparison of European regional air quality models using the information from the unified global assimilation system.

\section{GEMS Project - action plan}
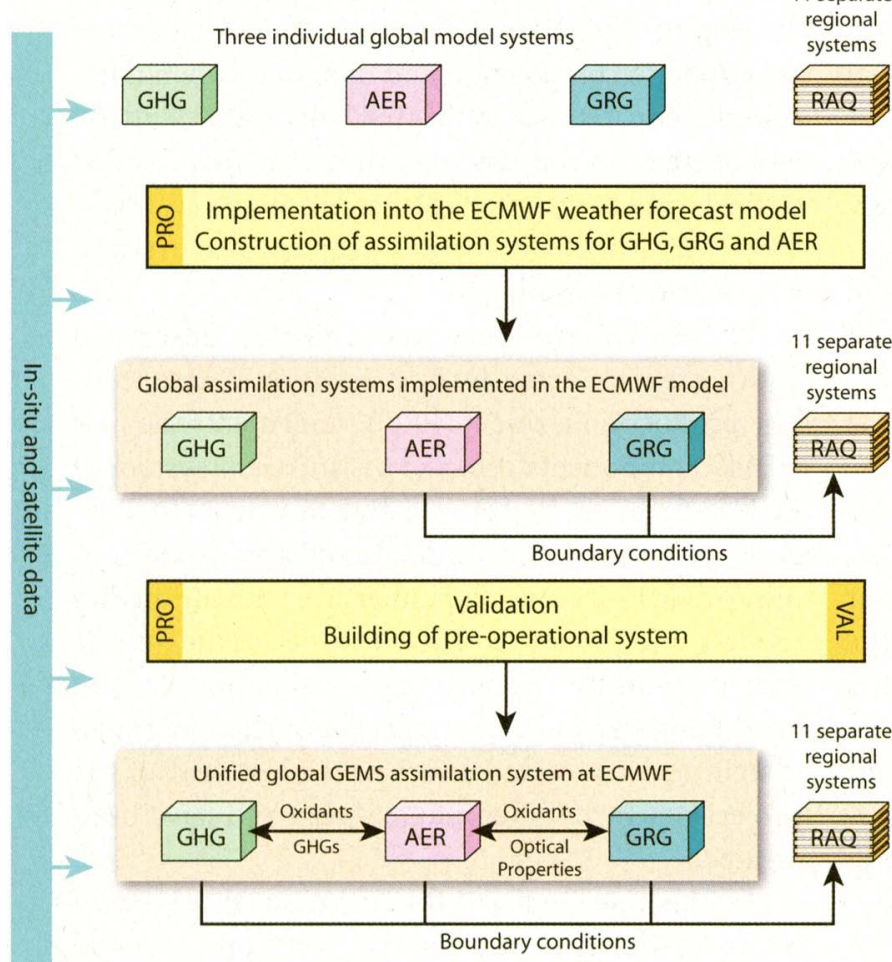

FIG. 2. Schematic illustrating the project action plan, and the links and flows of data and information between the main elements of the GEMS system: GHG, GRG, and AER, within the global atmospheric assimilation system at ECMWF, and RAQ. The PRO and VAL elements support the creation of the GEMS operational system. The three major steps are indicated on the time axis on the right-hand side of the figure and are discussed.

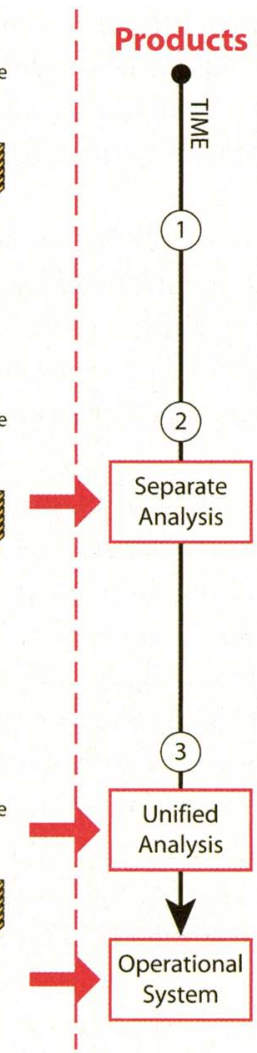

- Upgrade the elements of the data assimilation system based on validation experience.

Step 3:

- Build preoperational system and interfaces to partners.

- Produce a unified reanalysis for greenhouse gases, reactive gases, and aerosols.

- Prepare to deliver global atmospheric composition forecasts as well as regional air quality ensemble forecasts for the operational phase.

In the following the aims of the individual elements of the GEMS project and their current status will be described.

PRODUCTION SYSTEM-PRO. The objective of the production element is the implementation of the new GEMS components into the assimilation system at ECMWF in cooperation with the modeling teams. The four-dimensional variational data assimilation (4DVAR) system has been extended with greenhouse gases, reactive gases, and aerosols. Substantial efforts have been devoted to meeting the modeling needs of the project. The IFS model has introduced the generic capability to advect trace species by the model's dynamics, and to include them in the parameterizations representing convection and vertical diffusion. Inline parameterizations have been implemented for greenhouse gases and aerosols, with surface fluxes specified either climatologically (e.g., for $\mathrm{CO}_{2}$ ) or dynamically (e.g., for some aerosol types). Year-long test runs with specified meteorology and free-running chemistry have provided valuable checks on the models.

To actually assimilate the various measurements, observation operators have been coded that match the modeled variables to the 
actual observations. Depending on the type of measurement, the observation operator may be either a fast radiative transfer model, a simple integration to a weighted column amount, or a function that calculates the total optical depth.

4DVAR (Rabier et al. 2000) consists of finding an initial state of the atmosphere that best fits the observations within the data assimilation window using the short-term model forecast for this initial state (the "first guess" or "background") as a constraint. The fit depends on the specified error statistics of both the observations and the model forecast. Because the observations can be quite sparse, the effect of these observations on the adjusted initial state will depend significantly on the error statistics of the first guess. Considerable effort therefore goes into defining these error statistics, especially the spatial correlations. Within GEMS, unknown territory is being explored by defining error statistics for the model runs of the various atmospheric composition variables. First attempts have used the so-called National Meteorological Center (NMC) method and are described in Benedetti and Fisher (2007). The method estimates error statistics by comparing 12- and 24-h forecasts that end at the same time but start at different times. It therefore mainly accounts for errors in the model transport and uncertainties in the initial conditions.

Another important task within the PRO element is the bias correction of the various observations to a common standard (ideally defined by the most accurate observations, e.g., radiosondes, surface flasks). This is not a trivial task, because biases can depend on many variables and it is also possible accidentally to adjust the observations toward a model bias.

A key requirement of the GEMS modeling and assimilation capability is an accurate representation of the stratospheric Brewer-Dobson circulation, which is involved in the control of the distribution of many stratospheric constituents and in key aspects of troposphericstratospheric exchange. There has been important improvement in this regard since the completion of the 40-yr ECMWF Re-Analysis (ERA-40) in 2002 (Monge-Sanz et al. 2007).

\section{GREENHOUSE GASES-}

GHG. The objective of the greenhouse gas element is the development of a preoperational system to monitor the concentrations of greenhouse gases and their associated surface sources and sinks, and to attribute these sources and sinks to controlling processes. The system for greenhouse gases and for the inference of surface fluxes will be one of the first preoperational systems and will provide increased scientific insight into the carbon cycle, as requested by the Kyoto Protocol.

Based on an initial one-dimensional variational data assimilation (1DVAR) $\mathrm{CO}_{2}$ system, described by Engelen and McNally (2005), the ECMWF IFS model has now been extended to include $\mathrm{CO}_{2}$ as a model variable with prescribed surface sources and sinks. Figure 3 compares the simulated seasonal cycle of the $\mathrm{CO}_{2}$ concentration in the Northern and Southern Hemispheres in the extended IFS model with observations from GlobalView- $\mathrm{CO}_{2}$ (2003). The figure shows good qualitative agreement for the seasonal cycle, with $\mathrm{CO}_{2}$ being slightly overestimated by the simulation in the Northern Hemisphere summer/autumn and slightly underestimated in the Southern Hemisphere throughout the year. The IFS $\mathrm{CO}_{2}$ model also participated in the latest Atmospheric Tracer Transport Model Intercomparison Project (TRANSCOM) experiment (Law et al. 2007), in which the various models were compared to in situ observations. The IFS model was among the better models in terms of simulating seasonal and diurnal cycles as well as synoptic variations.

Currently, radiance observations from the Atmospheric Infrared Sounder (AIRS) and the Infrared Atmospheric Sounding Interferometer (IASI) are used in the 4DVAR system to constrain the atmospheric $\mathrm{CO}_{2}$ concentrations. This observational constraint will be extended to include data from the Cross-Track Infrared Sounder (CrIS), and the Orbiting Carbon Observatory (OCO) and Greenhouse Gases Observing Satellite (GOSAT) when data become available. A significant advantage of the 4DVAR system is that
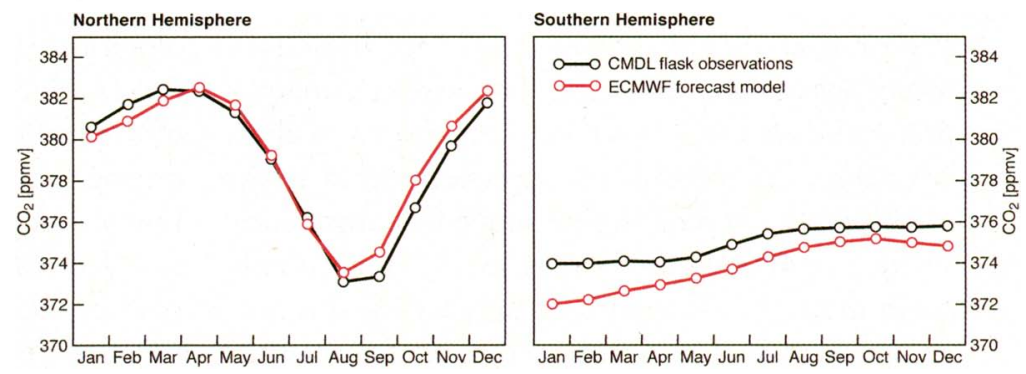

FIG. 3. Comparisons between GlobalView surface flask measurements of $\mathrm{CO}_{2}$ (black) and a year-long run of the extended IFS model (red) where the meteorology is reinitialized every $12 \mathrm{~h}$ by the operational analysis. 
Monthly mean $\mathrm{CO} 2$ column-averaged mixing ratio between $150 \mathrm{hPa}$ and $700 \mathrm{hPa}$ Reanalysis using AIRS observations August 2003

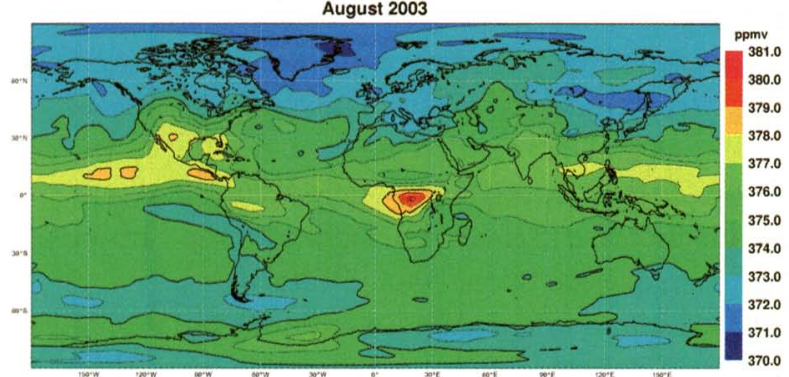

Monthly mean $\mathrm{CO} 2$ column-averaged mixing ratio between $150 \mathrm{hPa}$ and $700 \mathrm{hPa}$ Difference between reanalysis and simulation

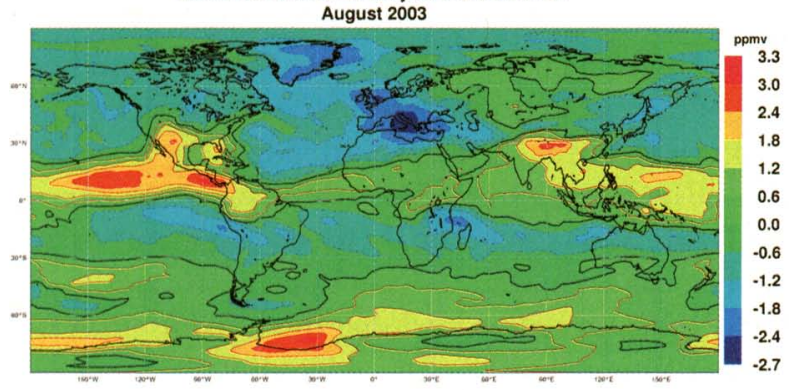

Monthly mean $\mathrm{CO} 2$ column-averaged mixing ratio between $150 \mathrm{hPa}$ and $700 \mathrm{hPa}$ Unconstrained model simulation August 2003
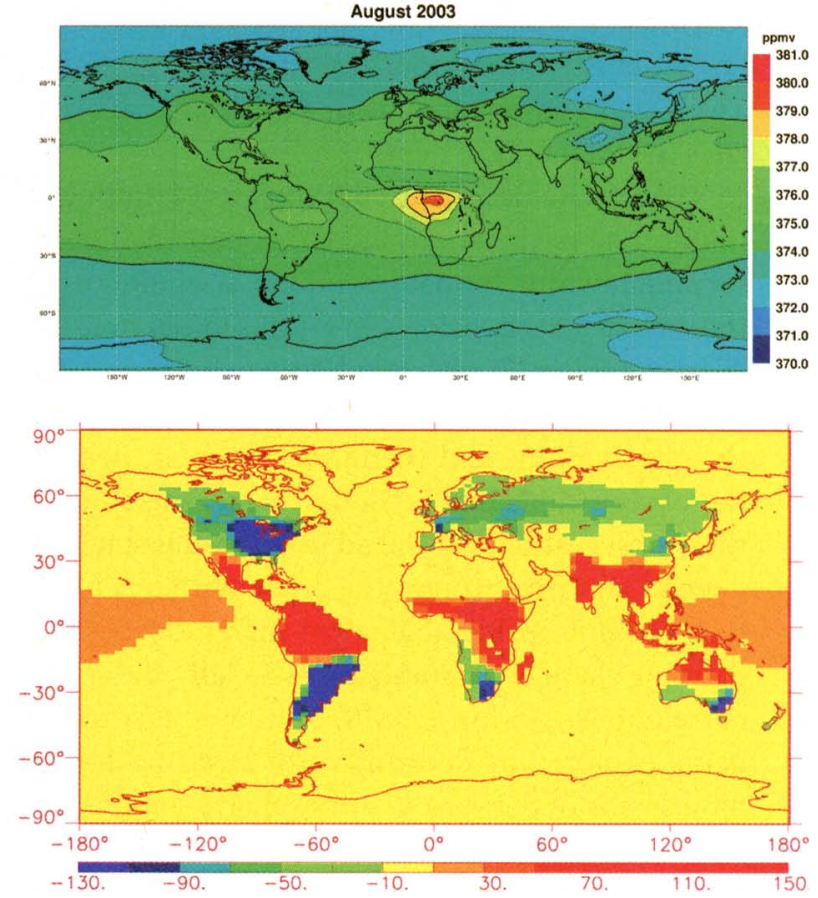

Fig. 4. (top left) Monthly mean total column $\mathrm{CO}_{2}$ after 8 months of assimilation using AIRS information on $\mathrm{CO}_{2}$ shows small but significant changes compared to (top right) a simulation with unconstrained $\mathrm{CO}_{2}$. The (bottom left) differences, also known as the atmospheric increments, are then used in a flux inversion to estimate (bottom right) flux increments relative to the prescribed flux climatology. Units are ppmv for the atmospheric $\mathrm{CO}_{2}$ plots and $\mathrm{gC} \mathrm{m}^{-2}$ for the flux increments plot.

relevant atmospheric parameters, such as temperature and humidity, are constrained by various other observational data sources at the same time.

The atmospheric $\mathrm{CO}_{2}$ fields provided by the 4DVAR system are then used in a variational Bayesian inversion system [based on the work described by Chevallier et al. (2005)] to produce global time-evolving maps of surface $\mathrm{CO}_{2}$ fluxes (on a monthly or quarterly basis). Observations from the various surface flask networks will be included at a later stage. The Laboratoire de Météorologie Dynamique Zoom (LMDZ) model (Hauglustaine et al. 2004) at the Laboratoire des Sciences du Climat et l'Environnement (LSCE) is used for these flux inversions. A two-step process (atmospheric analysis first and then a flux inversion) was chosen to allow large time windows for the inversion (up to a year of observational data in one single flux inversion). While the 4DVAR analysis at ECMWF optimally combines all of the available satellite data, it is limited to short analysis windows that do not allow for a proper flux estimate.

Figure 4 shows first results from a preliminary $1-y r$ data assimilation run using AIRS information on $\mathrm{CO}_{2}$. The AIRS retrospective analysis (top left) shows small but significant changes to a simulation with unconstrained $\mathrm{CO}_{2}$ (top right). Most of these changes are corrections of errors in the atmospheric $\mathrm{CO}_{2}$ caused by inaccuracies in the prescribed surface fluxes. Therefore, these differences (bottom left) between the assimilation and the unconstrained simulation can be interpreted as corrections to the prescribed surface fluxes (bottom right) using the variational flux inversion system. The best aspects of inverse- and forward-modeling techniques will be combined to attribute the inferred $\mathrm{CO}_{2}$ sources and sinks to geographical regions and causes. Terrestrial ecosystem models constrain the internal ecophysiological parameters of processes determining $\mathrm{CO}_{2}$ fluxes. Figure 5 shows an example of a simulation of the carbon fluxes from the terrestrial biosphere during the 2003 heat wave in Europe. The integration of independent satellite retrievals, carbon model simulations, and in situ aircraft observations will provide important new insights on the variability of $\mathrm{CO}_{2}$ in the troposphere and will thus help to constrain better the carbon cycle.

In a similar way to $\mathrm{CO}_{2}, \mathrm{CH}_{4}$ has also been added to the IFS system. Methane column retrievals are taken from the SCIAMACHY instrument and are 
used to constrain the atmospheric concentrations. Observations from the IASI instrument will be added as well. An offline flux inversion then uses these atmospheric fields to obtain better estimates of the surface fluxes. Again, we expect valuable new insight on the roles of transport, anthropogenic activity, biomass burning, and other processes on the budget of methane.

\section{GLOBAL REACTIVE GASES-}

GRG. The objective of the global reactive gases element is to set up a preoperational data assimilation system for chemically reactive gases within the ECMWF IFS system that is capable of providing global products on a day-by-day basis. For the assimilation of tropospheric reactive gases, it is essential to use an advanced chemistry scheme in the assimilation system. Because it is premature to introduce a full chemistry representation in the IFS model, we have used the OASIS4 software (see information online at www.cerfacs.fr/globc/software/ oasis/oasis.html) in a two-way coupling of the IFS model to each of the three participating chemistry transport models (CTMs): Modélisation de la Chimie Atmospherique Grand Echelle (MOCAGE; Josse et al. 2004; Bousserez et al. 2007), Model for OZone And Related chemical Tracers (MOZART; Horowitz et al. 2003; Kinnison et al. 2007), and Transport Model 5 (TM5; Krol et al. 2005). The use of multiple models provides an indication of the uncertainty in the chemical modeling. An example of the different output from each model is shown in Fig. 6 through simulated and observed monthly mean CO columns for February 2003. The MOZART CTM has been chosen as the model to be employed in the bulk of the development and testing of the global GEMS system because of its satisfactory scientific performance and its greater computational efficiency on ECMWF's parallel scalar high-performance computing system.

The forward-modeling part of the data assimilation system has been set up such that IFS supplies meteorological data at high temporal resolution to the coupled CTM. The IFS has been extended to simulate the transport for the chemical tracers $\mathrm{O}_{3}, \mathrm{NO}_{x}, \mathrm{CO}$, $\mathrm{SO}_{2}$, and $\mathrm{HCHO}$. In the coupled system, the CTM provides to the IFS initial conditions for these tracers and the 3D tendency fields accounting for source and sink processes not included in the IFS, such as chemical conversion, emissions, and deposition. The IFS model closely imitates the CTMs' simulations of the five tracers for up to $48 \mathrm{~h}$.

The five main tracers were chosen for their detectability by UV visible or near-infrared remote sensing and are constrained by the observations from various satellite instruments within each data assimilation window. The changes in concentration resulting from these observational constraints can then be fed back to the coupled CTM at the start of the next assimilation window. The $\mathrm{NO}_{2}$ observations are converted to the $\mathrm{NO}_{\mathrm{x}}$ model variable by means of a simple diagnostic operator based on clear-sky $\mathrm{NO}_{2}$ photolysis rates (Landgraf and Crutzen 1998), cloud optical depth (Krol and van Weele 1997), temperature, and ozone concentration. The direct simulation of $\mathrm{NO}_{2}$ was not feasible because the fast $\mathrm{NO}_{2}-\mathrm{NO}$ interconversion could not be captured satisfactorily.

As an example, we show in Fig. 7 the capability of the coupled IFS-MOZART system to assimilate CO column data from the Measurements of Pollution in the Troposphere (MOPITT) instrument. Assimilation of MOPITT CO columns leads to reduced values in the tropics and increased values in the extratropics relative to a control run without data assimilation. Note that the largest changes between the two runs occur in regions with extensive biomass burning (tropical Africa and eastern Siberia). Comparisons with independent Measurements of Ozone by Airbus In-Service Aircraft (MOZAIC) data (Nedelec et al. 2003) are presented in Fig. 8. In general, CO profiles from the assimilation run agree better with the 

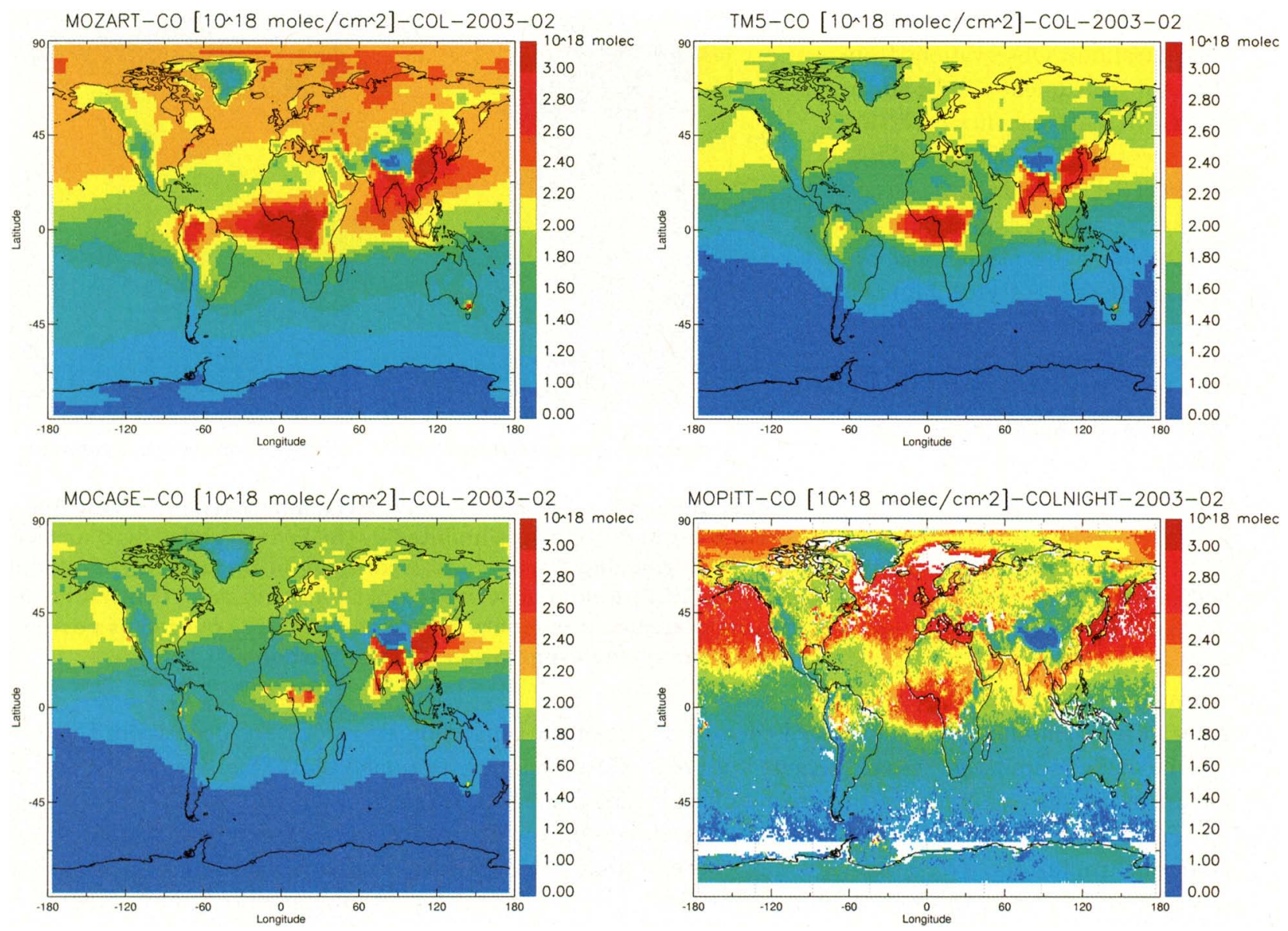

Fig. 6. Monthly mean CO columns for Feb 2003 from the (top left) MOZART, (top right) TM5, and (bottom left) MOCAGE models, all driven by a dedicated meteorological reanalysis for 2003 carried out by ECMWF. (bottom right) For a qualitative comparison, $\mathrm{CO}$ column retrievals from the MOPITT instrument are shown for the same month (MOPITT level 3 data; MOPITT averaging kernels have not been applied, see http://mopitt. eos.ucar.edu/mopitt).

MOZAIC data than CO profiles from the control run. For a more chemically active gas, such as ozone, the improvement is weaker, but is still significant as shown in the right panel of Fig. 8 for a profile over Frankfurt, Germany.

AEROSOLS-AER. The objective of the aerosol element is to set up a preoperational data assimila- tion system for aerosols within the ECMWF IFS, providing global products on a day-by-day basis. The core ECMWF meteorological model has been extended to include mineral dust and marine sea salt aerosol, as well as organic matter, black carbon, tropospheric sulfur, and background stratospheric aerosol as model variables. Dynamical parameterizations have been implemented for land sources of
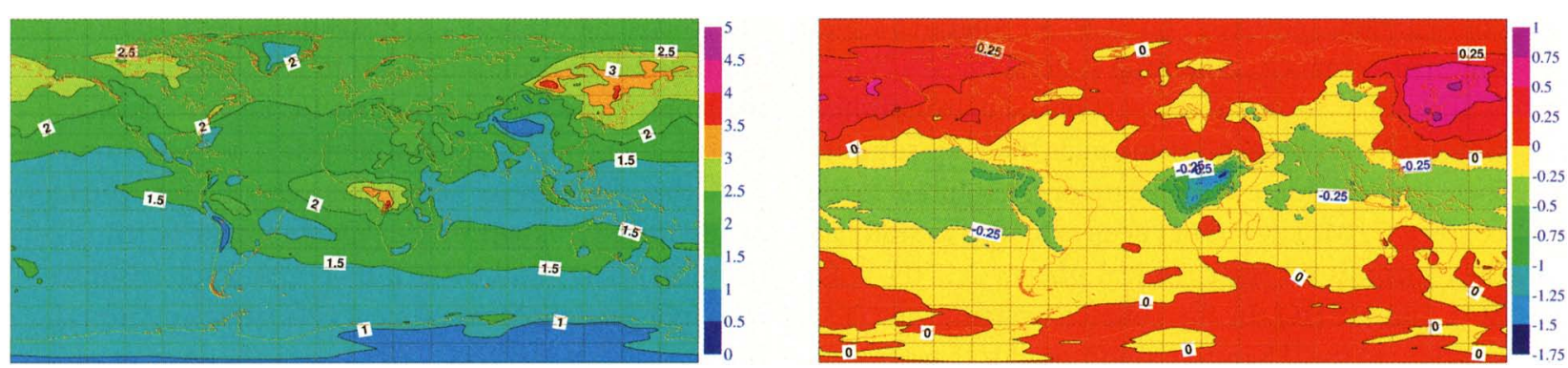

FIG. 7. Mean total columns of $\mathrm{CO}\left(10^{18}\right.$ molecules $\left.\mathrm{cm}^{-2}\right)$ for the period of $15-30 \mathrm{Jul} 2003$. (left) Reanalysis using MOPITT data and (right) difference between the reanalysis and the unconstrained model simulation. 
mineral dust and oceanic sources of sea salt particles. Climatological emission inventories are used for the other aerosol variables. The calculated aerosol optical characteristics can be averaged over any spectral interval and used for shortwave flux and radiance calculations. Finally, a stratospheric aerosol scheme that is consistent with that for tropospheric sulfate will be implemented to account for volcanic and nonvolcanic periods.

Figure 9 shows a simulation of the aerosol module implemented into the IFS model system showing a major extensive intrusion of Saharan dust into Europe. The desert origin of the high aerosol loads over Europe is also shown by a Moderate Resolution Imaging Spectroradiometer (MODIS) visible image for the same day.

The observational operator for the aerosol optical depth along with its tangent linear and adjoint have been coded and included in IFS to allow for the assimilation of aerosol satellite products. In the initial phase, aerosol optical depth (AOD) is being used as the main observation, but a radiative transfer code (6S; Vermote et al. 1997) is being adapted for
Co, Osaka

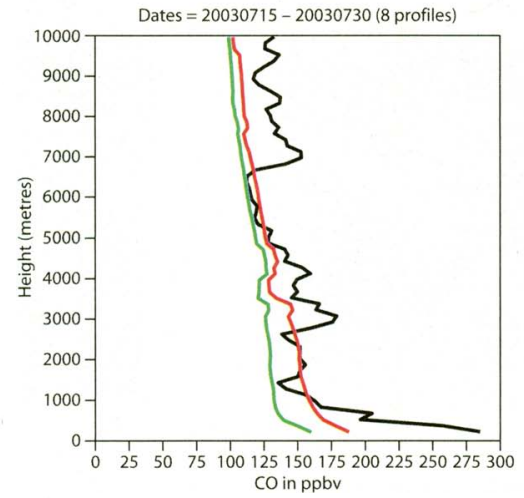

CO in ppbv
$\mathbf{O}_{3}$, Frankfurt

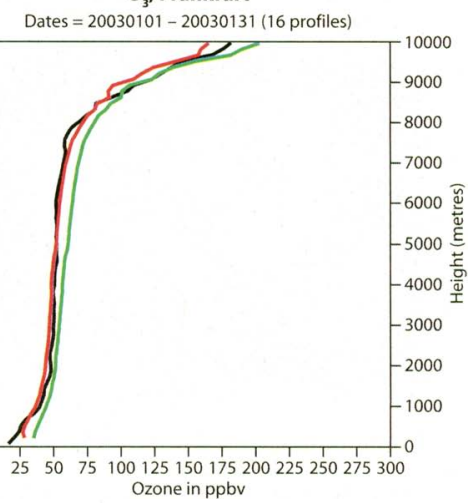

FIG. 8. Average vertical profiles of (left) CO over Osaka, Japan, and of (right) $\mathrm{O}_{3}$ over Frankfurt, Germany, from MOZAIC observations (black), the control run (green), and the assimilation run (red).

assimilating aerosol radiances instead of aerosol products at a later stage of the project. Figure 10 shows the global aerosol optical depth distribution of a run where aerosols are not constrained by satellite observations (upper left panel) compared with an assimilation run using MODIS data to constrain the aerosol (upper right panel). Assimilation generally improves the aerosol distribution, especially over areas with extensive biomass burning and other anthropogenic sources, which are not well represented in the simulation. For comparison, the figure also shows the AOD distribution directly
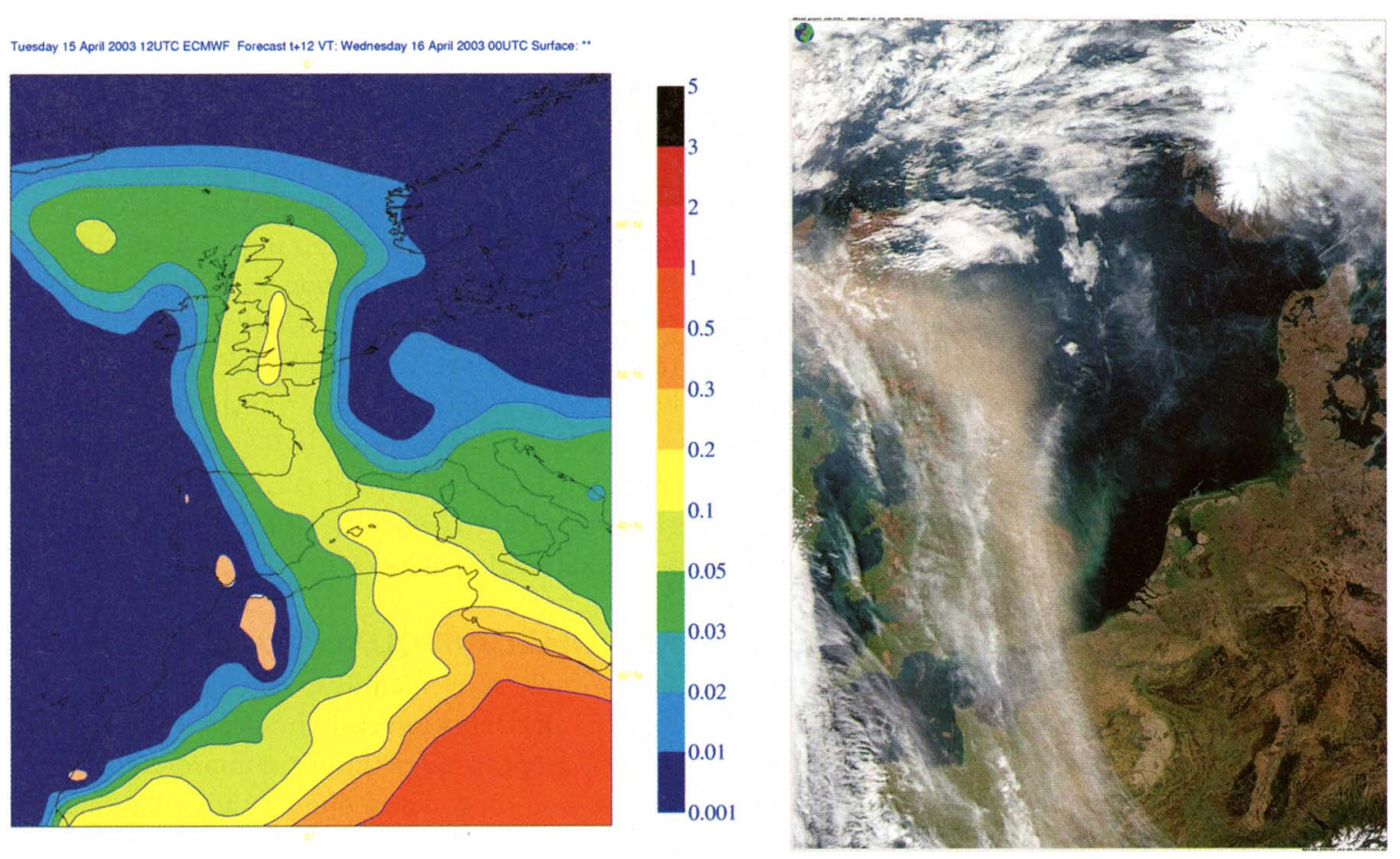

FIG. 9. Comparison of a dust aerosol optical depth at $550-\mathrm{nm}$ simulation (12-h forecast for 0000 UTC 16 Apr 2003) from (left) the aerosol model implemented into the IFS model with (right) a MODIS visible image over northwestern Europe on 16 Apr. 
Aerosol Optical Depth at $550 \mathrm{~nm}$ from Unconstrained Model Run July 2003

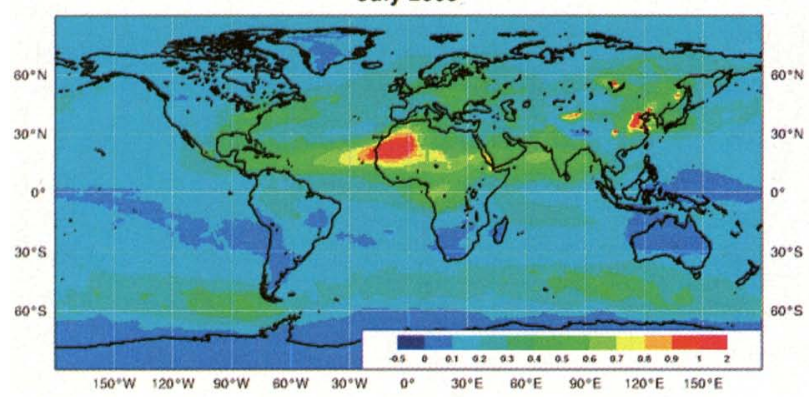

MODIS Terra MOD08-M3.005 Aerosol Optical Depth at $550 \mathrm{~nm}$ [unitless] July 2003

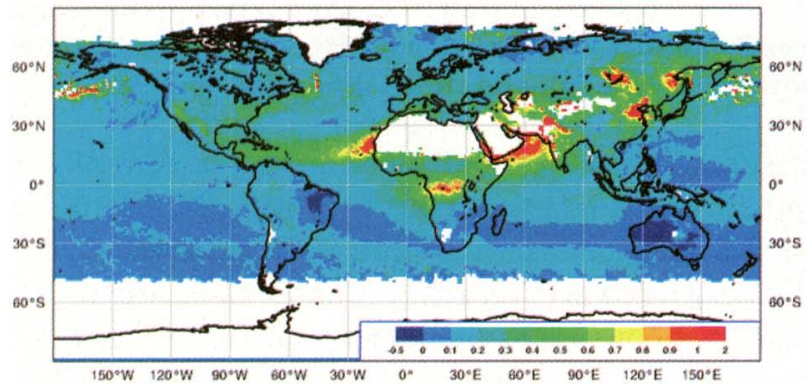

Aerosol Optical Depth at $550 \mathrm{~nm}$ for Reanalysis using MODIS AOD July 2003

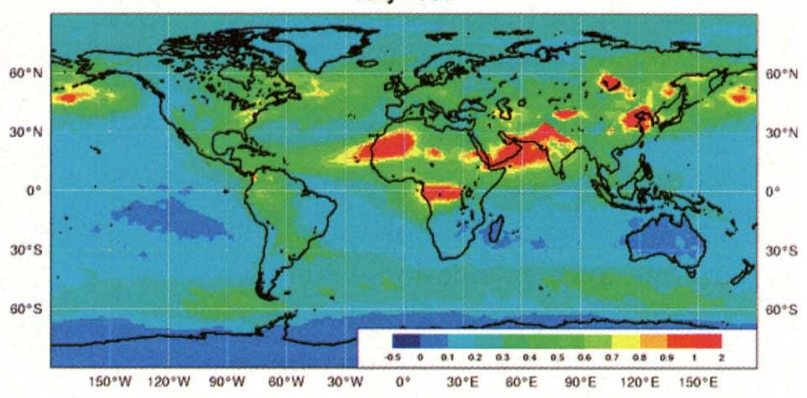

MISR Terra Aerosol Optical Depth at $557.5 \mathrm{~nm}$ [unitless] July 2003

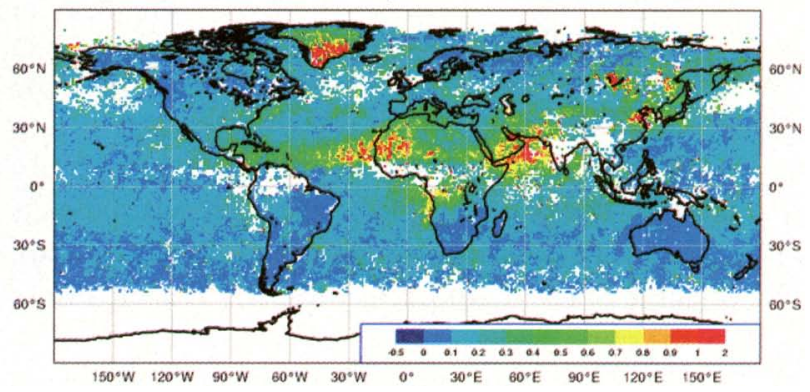

Fig. 10. Comparison of aerosol optical depth from an unconstrained simulation using (top left) the new aerosol module implemented into the IFS model, (top right) an assimilation run constrained with MODIS data, and (bottom right) the aerosol optical depth as observed by MODIS for I-I5 Aug 2003. For comparison, (bottom right) the optical depth observed by the Multiangle Imaging Spectroradiometer (MISR) is shown.

from MODIS (bottom left) and from unassimilated MISR data (bottom right).

The new aerosol assimilation system is currently being carefully evaluated with aerosol-sensitive radiative quantities from ground-based data, as well as with aerosol physical-chemical properties from ground-based networks, extensive observational supersites, and field campaigns.

GEMS aerosol products for end users will include four-dimensional distributions of atmospheric aerosols at around $100-\mathrm{km}$ resolution, visibility range (e.g., for tourism and air traffic), photosynthetically active radiation, concentrations and chemical composition of particulate matter, and aerosol information that can be used for atmospheric corrections in satellite data.

VALIDATION-VAL. The objective of this element is the validation of the unified, integrated global GEMS system in a concerted effort in the last year of the project (in 2008/09). The construction of the integrated GEMS system from the three subsystems (GHG, GRG, and AER) will introduce interactions between these components. Therefore, the resulting model fields and data assimilation analyses will differ from that produced by the individual subsystems.
These interactions, in combination with 4DVAR, are very powerful because they permit the efficient transfer of information from the observations to unobserved variables and regions of the globe. Special attention is needed, however, to specify and control model and measurement biases in order to avoid unphysical feedbacks. Retrospective analysis runs will be validated with available independent observations (in situ, aircraft, balloon, satellite). All GEMS partners are involved in this activity. The implementation and performance of the GEMS system will be assessed, with a focus on transport aspects that are relevant to all subprojects. The scientific results obtained from the retrospective analysis will be carefully checked before the GEMS products become preoperational in 2009.

REGIONAL AIR QUALITY-RAQ. The objective of the RAQ element is to enhance and improve regional air quality forecasts, hindcasts, and analyses across Europe through the use of improved information on long-range transboundary air pollution from the global GEMS elements. The GEMS assessments profit from the availability of an ensemble of excellent air quality models on the European scale. The GEMS regional models consider a common European 
domain $\left(35^{\circ}-70^{\circ} \mathrm{N}, 15^{\circ} \mathrm{W}-35^{\circ} \mathrm{E}\right)$ for ensemble activities and intercomparisons. Vertical and horizontal resolutions depend upon the models; many started with $20-50-\mathrm{km}$ resolution, with a target resolution of 5-20 km. Nested domains at higher resolution are also being developed. The European-scale air quality modeling groups have established their interfaces to the GEMS archives and are preparing for the reception of GEMS meteorological and chemical boundary conditions. The data flows between the central site at ECMWF and the GEMS regional modeling partners are illustrated in Fig. 11.

As part of the validation work for the Europeanscale air quality models, in 2008/09 the GEMS partners are undertaking an extensive intercomparison of their products. The participating groups are making extensive forecast experiments using the same forecasting protocol for initial and boundary conditions on meteorology and chemistry, and as far as possible for surface anthropogenic and biogenic emissions. The use of a common forecasting protocol, a common forecast domain, common archiving, and common performance metrics allows for a thorough intercomparison of the regional systems. Included are metrics for assessing forecasts of basic chemical species and metrics specific to the user communities (e.g., air quality indices for human health and crop damage, and metrics for city-level forecasts). Dedicated software allows central verification and user-tailored assessments. Efforts have been made to agree upon a "memorandum of understanding" on observational data and forecast exchange for purely scientific and technical objectives with national and regional air quality agencies across Europe. In addition, some of the RAQ models will assimilate observational chemical data at high resolution along the lines of the work described in Elbern et al. (1997, 2007). This will ensure that all available data are used in an optimal way either on the global or regional scale.

All GEMS regional models (see Fig. 11) have been adapted to IFS output, and activities on ensemble air quality modeling have started. A first example of model spread for a specific case is illustrated in Fig. 12, which shows $\mathrm{NO}_{2}$ forecasts from four different models. Although the emissions, boundary conditions, and driving meteorology are the same for all models, there are clear differences between the models. Currently, this model spread will mainly be used to estimate the uncertainty of the model forecasts. Near-real-time ensemble products (e.g., in terms of the probability of exceedance of air quality thresholds) will be among the products to be tested and delivered in the RAQ operational phase. Along with this unprecedented effort on multimodel ensemble air quality forecasting, some of the project partners will investigate and evaluate the relative benefits obtained with ensembles using only one model, but varying meteorological input forcings or chemical reaction rates. With joint activities conducted in near-real time, collaboration and feedback with users and actors in the sector, and the buildup of a common understanding of key uncertainties and progress areas, GEMS is thus expected to move forward and harmonize practices among regional air quality forecast centers in Europe.

This work is conducted in the context of preparing the regional models for routine operational running at the end of the project, using the global products as boundary and/or initial conditions. The resulting assessments will be comprehensive and extensive, examining impacts on mean fields and on extreme events. One of the goals of GEMS is to assess the value of the GEMS data in epidemiological studies of the public health effects of long-range aerosols and reac-

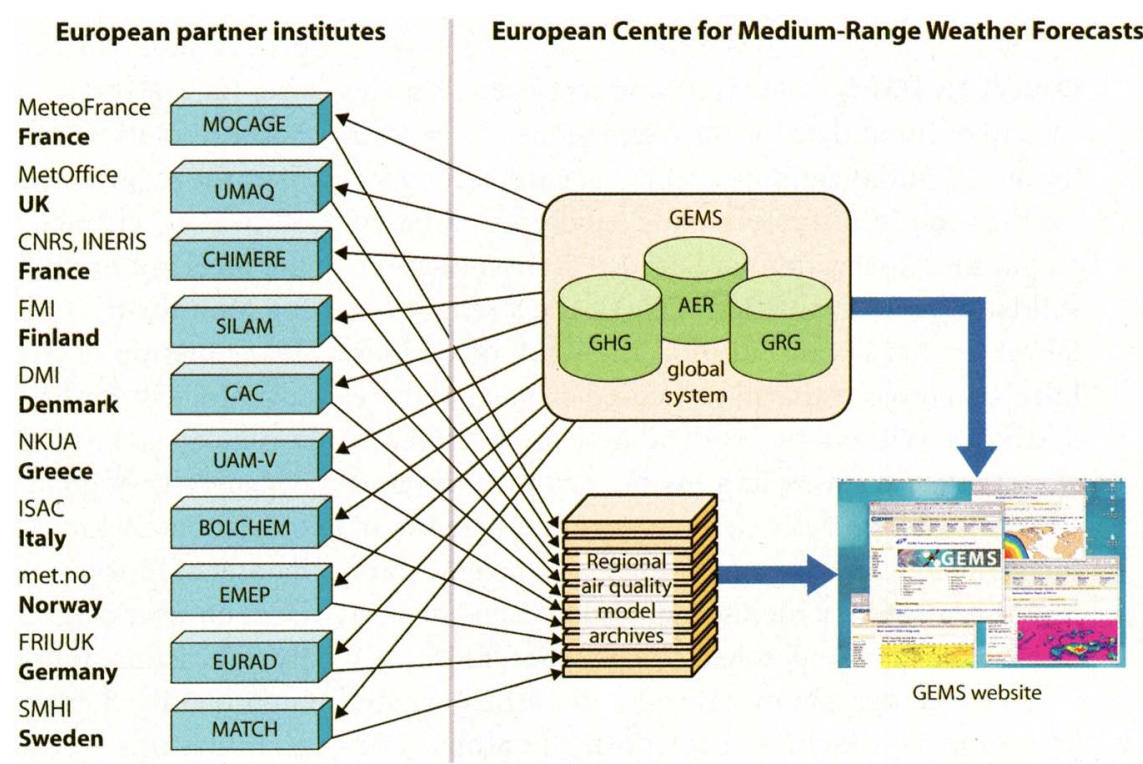

FIG. II. Illustration of the model data flows between the central site at ECMWF and the GEMS regional modeling partners. 

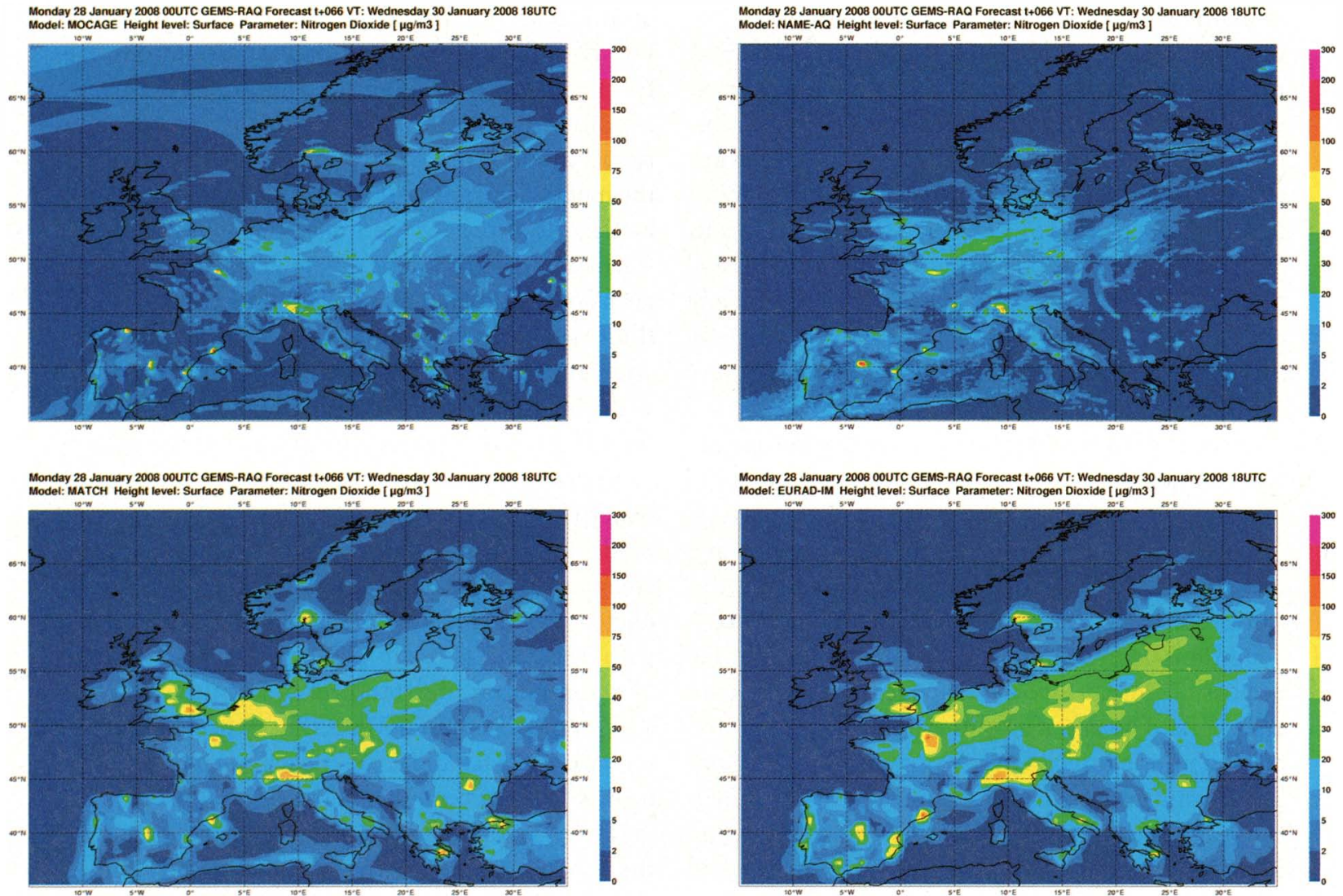

FIG. 12. Ensemble regional air quality forecasts: $66-\mathrm{h}$ forecast of nitrogen dioxide $\left(\mu \mathrm{g} \mathrm{m}^{-3}\right)$ valid at $1800 \mathrm{UTC} 30$ Jan 2008 from four European air quality model systems: (top left) MOCAGE, (top right) Numerical Atmospheric dispersion Modeling Environment (NAME), (bottom left) Multiscale Atmospheric Transport and Chemistry Model (MATCH), and (bottom right) European Radar (EuRAD).

tive gases. Preliminary studies are planned to identify the types of health effects that can be meaningfully studied using GEMS RAQ data.

DATA ISSUES. The GEMS project needs a great variety of input data. Surface emissions are needed for model initialization, satellite data are needed for assimilation into the IFS model, and ground-based and in situ observations are needed for assimilation, validation, and evaluation. One of the strengths of GEMS is that it can build on the work of various European projects that have focused on parts of these databases. Without the work of these projects GEMS would suffer to realize its aims, but on the other hand GEMS is able to fully demonstrate the benefits of these other projects by combining the complementary results in a coherent monitoring system. Hereafter, we discuss the main input data streams for GEMS.

The specification of natural and anthropogenic emissions is a key issue for both the global and regional elements of the GEMS project. GEMS is making use of the global anthropogenic emis- sions calculated by the European Reanalysis of the Tropospheric Chemical Composition over the Past 40 Years (RETRO; online at http://retro.enes.org) project. A new high-resolution inventory of emissions over Europe (hourly, weekly, monthly, and annual, at $5-\mathrm{km}$ resolution) has been created within GEMS to meet the requirements of the high-resolution models of the RAQ element. This new inventory is based on the Steering Body to the Cooperative Programme for Monitoring and Evaluation of the Long-Range Transmission of Air Pollutants in Europe (EMEP) inventory of anthropogenic emissions. The EMEP inventory is the up-to-date reference in Europe, and is generally of good quality, but has a resolution of only about $50 \mathrm{~km}$. The creation of a high-resolution dataset of European emissions, shared and used by a large number of groups involved in regional air quality forecasting, represents an important step toward high-quality chemical weather forecasts.

Emissions by biomass burning are a key issue for the GEMS project across all elements. A detailed analysis of the current global observation 
system performed jointly with the European projects Harmonised coordination of Atmosphere, Land and Ocean projects of the GMES backbone (HALO), Integrated GMES Project on Land Cover and Vegetation (GEOLAND), and Atmospheric Composition Change: The European Network of Excellence (ACCENT) has shown that none of the currently existing biomass-burning products provides all of the information required by GEMS. However, the different observations are complementary and contain all of the information required (Kaiser et al. 2006), and GEMS will ensure that biomass-burning emissions are treated consistently for all of the relevant variables. The Global Fire Emissions Database, version 2 (GFEDv2) inventory, based on MODIS fire hot-spot observations and the Carnegie-Ames-Stanford Approach (CASA) vegetation model, is a well-established retrospective global fire emission inventory with monthly time resolution (van der Werf et al. 2006). It contains all species that are relevant for GEMS and is used to prescribe the wildfire emissions for the GEMS retrospective analyses. It has been resampled to an 8-day time step using MODIS fire hot spots (Giglio et al. 2003) in order to improve the accuracy of these analyses. Current efforts are aimed at refining the time resolution further and providing the emissions in real time. Additionally, the use of the Fire Radiative Power (FRP) product from the Spinning Enhanced Visible and Infrared Imager (SEVIRI; Wooster et al. 2003; Roberts et al. 2005) is being studied in the EUMETSAT FRP Evaluation (FREEVAL) project. SEVIRI's FRP will be made operationally available in real time by EUMETSAT and is expected to yield the amount of wildfire emission in Africa and southern Europe more accurately than GFEDv2.

High-quality satellite data are needed within GEMS, and considerable help has been provided by major space agencies, including ESA, EUMETSAT, NASA, and National Environmental Satellite, Data, and Information Service (NESDIS), and by many research projects/institutes in the acquisition of the very large amounts of satellite observations that are needed by the project. Because the satellite data for assimilation are acquired, they are reformatted in BUFR and archived at ECMWF. Parallel efforts are underway to acquire and archive routine in situ environmental data. GEMS is liaising with agencies such as the Japan Aerospace Exploration Agency (JAXA), National Institute for Environmental Studies (NIES), and NASA for the optimal use of information from key future missions, such as GOSAT and OCO, and with ESA and EUMETSAT to ensure optimal avail- ability of radiance data and products in general for the post-GEMS period.

Model validation relies, apart from additional independent satellite data products, mainly on in situ data from various sources, both from observational networks [e.g., WMO/Global Atmosphere Watch (GAW), NOAA/Earth System Research Laboratory (ESRL), EMEP, NDACC, MOZAIC, Aerosol Robotic Network (AERONET), and European Aerosol Research Lidar Network (EARLINET)], some of which provide data in near-real time or plan the transition toward near-real-time data delivery, and from campaign data.

Satellite data provision in 2009-19. The availability of satellite data provision is a key issue in planning the first decade of operational GEMS activity. The current Envisat-EOS era provides a wealth of observational capability from space, which GEMS will aim at exploiting. There are, however, challenges in the availability of satellite data beyond 2010. The operational METOP series provides information on aerosols and trace gases. In addition, information about aerosols, land properties, and oceans will come from the operational NPOESS series. An Along-Track Scanning Radiometer (ATSR)-like instrument on ESA's Sentinel-3 will also provide aerosol capability. Information on greenhouse gases will be provided with operational advanced sounders [IASI since early 2007, and CrIS on the NPOESS Prepartory Project (NPP) in 2009] for upper-tropospheric measurements, and the research OCO and GOSAT missions from 2009 onward. The main gap in satellite provision is an effective atmospheric chemistry observing capability from space that can be exploited for air quality issues. No such dedicated missions are committed beyond the demise of Envisat and EOS Aura. Missions currently under study could not fly before 2015 , even in a favorable funding environment.

\section{EUROPEAN INSTITUTIONAL ARRANGE- MENTS NEEDED FOR A TRANSITION TO OPERATIONS IN 2009. The aim of the GEMS} project is to be scientifically and technically ready for the transition of the global and regional GEMS systems to formal preoperational status by mid-2009, at the end of the project. The initial post-2008 preoperational configuration of the GEMS assimilation system will be at $\sim 100-\mathrm{km}$ resolution. The operational configuration will evolve thereafter to realize benefits for the higher-resolution NWP systems operated within Europe. Some elements of the GEMS suite (e.g., aerosol) could prove to be of sufficient value to 
justify early implementation in the ECMWF NWP suite, and GEMS aerosol analyses may provide initial conditions for use in other NWP systems.

To ensure a successful transition it will be necessary to harmonize the necessary institutional arrangements. The actors will include the following:

- the European Commission, European Environment Agency (EEA), and European ESA;

- the national environmental agencies and regional environmental agencies of Europe; and

- the European national meteorological services, acting either singly or jointly through EUMETNET, together with ECMWF and EUMETSAT.

The institutional arrangements will address issues such as long-term funding, data sharing, and product dissemination. Currently, contract negotiations are underway with the European Commission to merge GEMS and the ESA-funded Protocol Monitoring for the GMES Service Element: Atmosphere (PROMOTE) project into the Monitoring of Atmospheric Composition and Climate (MACC) project. This project will start in June 2009.

SUMMARY. The GEMS project, funded by the European Commission within the GMES framework, aims to build a global preoperational monitoring/ forecasting system for atmospheric composition. It combines various sources of satellite data and in situ data to optimally constrain atmospheric fields of important greenhouse gases, reactive gases, and aerosols within a meteorological 4DVAR system. It also produces surface flux estimates for various species and provides air quality forecasts for the European domain. Much-improved ensemble air quality monitoring and forecasts are being delivered for the European domain. Combining the operational and research experience of ECMWF and partner institutes, the GEMS system provides a huge step toward operational monitoring of the Earth climate and air quality system. The project has made good progress since its start in spring 2005, and the major milestones and deliverables have been met. There is every reason to be confident that by May 2009 the GEMS project will deliver a new preoperational European system that can use both satellite and in situ data to monitor and provide global and regional forecasts of the dynamics, thermodynamics, and composition of the atmosphere, including greenhouse gases, reactive gases, and aerosols.
ACKNOWLEDGMENTS. GEMS is funded by the European Commission under the EU Sixth Research Framework Programme, Contract SIP4-CT-2004-516099. We are very grateful to our project officer Dr. Peter Breger for his consistent help and enthusiasm in developing and launching the GEMS program. We also acknowledge the many agencies that provided observational data. Guido van der Werf (Vrije Universiteit Amsterdam) has kindly resampled the GFEDv2 inventory to 8-day time resolution. Louis Gonzalez (LOA USTL) kindly provided the MODIS image (online at http://loaamma.univ-lillel.fr/ modissurvey; http://loaamma.univ-lillel.fr/AMMA). Dr. Anthony Hollingsworth sadly passed away on 29 June 2007. He was the initiator and coordinator of the GEMS project and is greatly missed as a person and for his significant contributions to the atmospheric sciences.

\section{REFERENCES}

Al-Saadi, J., and Coauthors, 2005: Improving national air quality forecasts with satellite aerosol observations. Bull. Amer. Meteor. Soc., 86, 1249-1261.

Baker, D. F., and Coauthors, 2006: TransCom 3 inversion intercomparison: Impact of transport model errors on the interannual variability of regional $\mathrm{CO}_{2}$ fluxes, 1988-2003. Global Biogeochem. Cycles, 20, GB1002, doi:10.1029/2004GB002439.

Benedetti, A., and M. Fisher, 2007: Background error statistics for aerosols. Quart. J. Roy. Meteor. Soc., 133, 391-405.

Bousserez, N., and Coauthors, 2007: Evaluation of MOCAGE chemistry and transport model during the ICARTT/ITOP experiment. J. Geophys. Res., 112, D10S42, doi:10.1029/2006JD007595.

CEOS, cited 2006: Satellite observation of the climate system, The Committee on Earth Observation Satellites (CEOS) response to the Global Climate Observing System (GCOS) implementation plan (IP), 50 pp. [Available online at www.ceos.org/pages/ CEOSResponse_101A.pdf.]

Chai, T., G. R. Carmichael, A. Sandu, Y. Tang, and D. N. Daescu, 2006: Chemical data assimilation of Transport and Chemical Evolution over the Pacific (TRACE-P) aircraft measurements. J. Geophys. Res., 111, D02301, doi:10.1029/2005JD005883.

Chevallier, F., M. Fisher, P. Peylin, S. Serrar, P. Bousquet, F.-M. Bréon, A. Chédin, and P. Ciais, 2005: Inferring $\mathrm{CO}_{2}$ sources and sinks from satellite observations: Method and application to TOVS data. J. Geophys. Res., 110, D24309, doi:10.1029/2005JD006390.

Dethof, A., and E. V. Holm, 2004: Ozone assimilation in the ERA-40 reanalysis project. Quart. J. Roy. Meteor. Soc., 130, 2851-2872. 
Elbern, H., H. Schmidt, and A. Ebel, 1997: Variational data assimilation for tropospheric chemistry modelling. J. Geophys. Res., 102, 15 967-15 985.

—, A. Strunk, H. Schmidt, and O. Talagrand, 2007: Emission rate and chemical state estimation by 4-dimensional variational inversion. Atmos. Chem. Phys., 7, 3749-3769.

Engelen, R. J., and A. P. McNally, 2005: Estimating atmospheric $\mathrm{CO}_{2}$ from advanced infrared satellite radiances within an operational four-dimensional variational (4D-Var) data assimilation system: Results and validation. J. Geophys. Res., 110, D18305, doi:10.1029/2005JD005982.

Farman, J. C., B. G. Gardiner, and J. D. Shanklin, 1985: Large losses of total ozone in Antarctica reveal seasonal $\mathrm{C} 1 \mathrm{Ox} / \mathrm{NOx}$ interaction. Nature, 315, 207-210.

Fonteyn, D., Q. Errera, M. De Maziere, G. Franssens, and D. Fussen, 2000: 4D-VAR assimilation of stratospheric aerosol satellite data. Adv. Space Res., 26, 2049-2052.

GCOS, 2004: Implementation plan for the Global Observing System for Climate in Support of the UNFCCC. GCOS-92, WMO/TD 1219, 153 pp.

_ 2006: Systematic observation requirements for satellite-based products for climate. Supplemental details of the satellite-based component to the "Implementation Plan for the Global Observing System for Climate in Support of the UNFCCC." GCOS-107, WMO/TD 1338, 103 pp.

Geer, A. J., and Coauthors, 2006: The ASSET intercomparison of ozone analyses: Method and first results. Atmos. Chem. Phys., 6, 5445-5474.

Generoso, S., F.-M. Bréon, F. Chevallier, Y. Balkanski, M. Schulz, and I. Bey, 2007: Assimilation of POLDER aerosol optical thickness into the LMDz-INCA model: Implications for the Arctic aerosol burden. J. Geophys. Res., 112, D02311, doi:10.1029/2005JD006954.

Giglio, L., J. Descloitres, C. O. Justice, and Y. J. Kaufman, 2003: An enhanced contextual fire detection algorithm for MODIS. Remote Sens. Environ., 87, 273-282.

Global Carbon Project, 2003: Science framework and implementation. Earth System Science Partnership (IGBP, IHDP, WCRP, DIVERSITAS) Report, Global Carbon Project Report 1, 69 pp.

GlobalView-CO2, 2003: Cooperative Atmospheric Data Integration Project-Carbon Dioxide. NOAA/ Climate Monitoring and Diagnostics Laboratory, CD-ROM. [Available online at ftp.cmdl.noaa.gov, Path: ccg/co2/GLOBALVIEW.]

Hauglustaine, D. A., F. Hourdin, L. Jourdain, M.-A. Filiberti, S. Walters, J.-F. Lamarque, and E. A.
Holland, 2004: Interactive chemistry in the Laboratoire de Météorologie Dynamique general circulation model: Description and background tropospheric chemistry evaluation. J. Geophys. Res., 109, D04314, doi:10.1029/2003JD003957.

Horowitz, L. W., and Coauthors, 2003: A global simulation of tropospheric ozone and related tracers: Description and evaluation of MOZART, version 2. J. Geophys. Res., 108, 4784, doi:10.1029/ 2002JD002853.

HTAP, 2007: Hemispheric Transport of Air Pollution 2007. Interim Report prepared by the Task Force on Hemispheric Transport of Air Pollution, within the framework of the Convention on Long-range Transboundary Air Pollution, Air Pollution Studies 16, United Nations, 146 pp.

IGACO, 2004: An Integrated Global Atmospheric Chemistry Observation theme for the IGOS partnership. GAW Report 15954 pp. [Available online at www.wmo.int/pages/prog/arep/gaw/documents/ gaw159.pdf]

Josse, B., P. Simon, and V.-H. Peuch, 2004: Rn-222 global simulations with the multiscale CTM MOCAGE. Tellus, 56B, 339-356.

Kaiser, J. W., and Coauthors, 2006: Observation requirements for global biomass burning emission monitoring. Proc. 2006 EUMETSAT Meteorological Satellite Conf., Helsinki, Finland, EUMETSAT, www.eumetsat.int/Home/Main/Publications/ Conference_and_Workshop_Proceedings/SP_ 1166193307834 ? $1=$ en.

Keeling, C. D., R. B. Bacastow, A. E. Bainbridge, C. A. Ekdahl Jr., P. R. Guenther, and L. S. Waterman, 1976: Atmospheric carbon dioxide variations at Mauna Loa Observatory, Hawaii. Tellus, 28, 538-551.

Kinnison, D. E., and Coauthors, 2007: Sensitivity of chemical tracers to meteorological parameters in the MOZART-3 chemical transport model. J. Geophys. Res., 112, D20302, doi:10.1029/2006JD007879.

Krol, M. C., and M. van Weele, 1997: Implications of variation of photodissociation rates for global atmospheric chemistry. Atmos. Environ., 31, 1257-1273.

_- and Coauthors, 2005: The two-way nested global chemistry-transport zoom model TM5: Algorithm and applications. Atmos. Chem. Phys., 5, 417-432.

Lahoz, W. A., and Coauthors, 2007: The Assimilation of Envisat Data (ASSET) project. Atmos. Chem. Phys., 7, 1773-1796.

Landgraf, J., and P. J. Crutzen, 1998: An efficient method for online calculations of photolysis and heating rates. J. Atmos. Sci., 55, 863-878.

Law, R. M., and Coauthors, 2008: TransCom model simulations of hourly atmospheric $\mathrm{CO} 2$ : experi- 


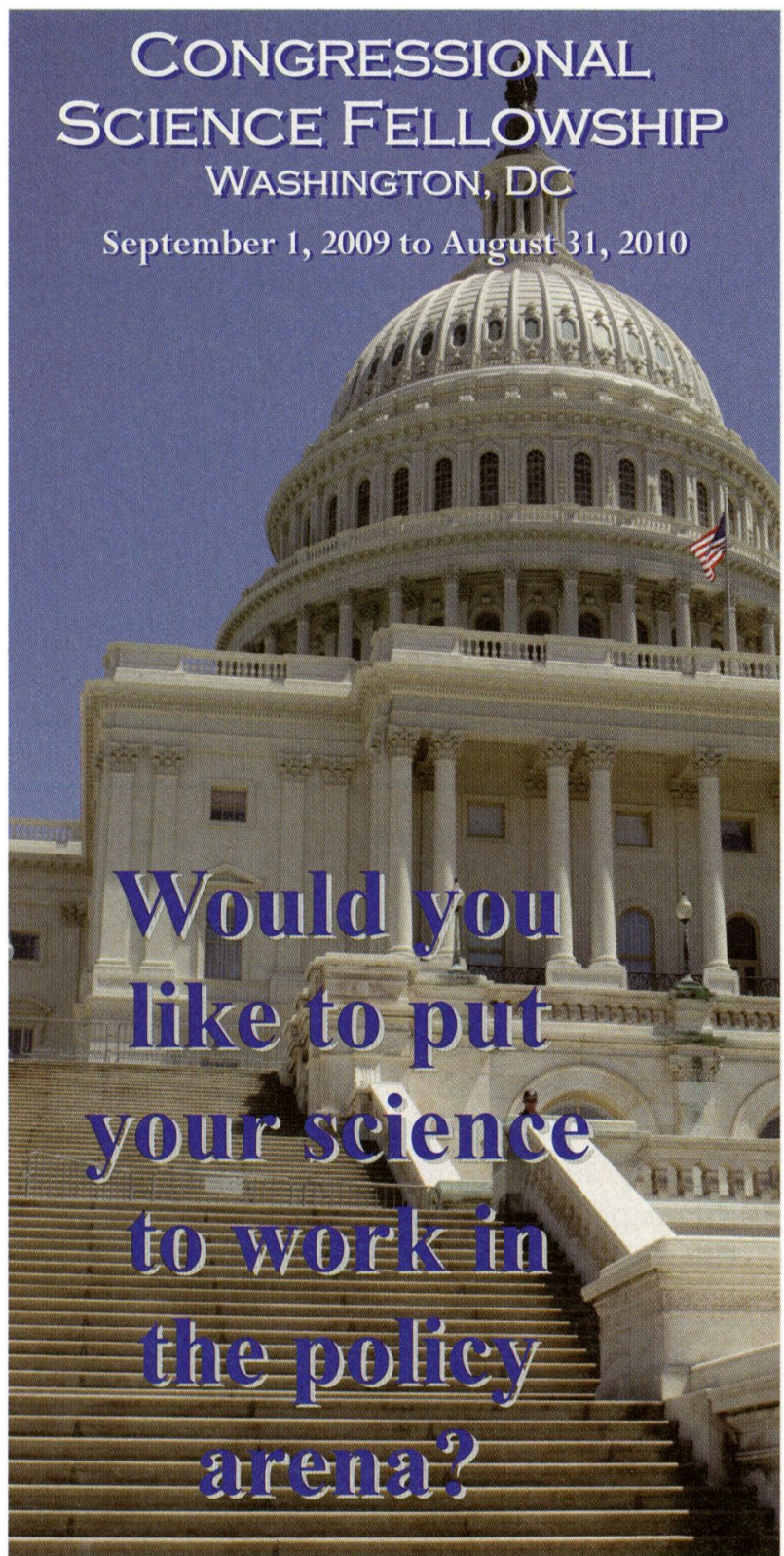

Work in Congress on science policy issues choosing from a wide variety of congressional offices. Receive a stipend of $\$ 50,000$ and moving/travel expenses up to $\$ 10,000$.

\section{WHO IS ELIGIBLE:}

$\checkmark \quad$ Ph.D. or equivalent in the atmospheric or related sciences

$\checkmark$ AMS Member (or applying)

$\checkmark$ U.S. Citizen

(Federal employees are not eligible)

Applicants should be comfortable working under demanding deadlines.

\section{WWW.AMETSOC.ORG/CSF}

mental overview and diurnal cycle results for 2002, Global Biogeochem. Cycles, in press, doi:10.1029/ 2007GB003050.

Monge-Sanz, B. M., M. P. Chipperfield, A. J. Simmons, and S. M. Uppala, 2007: Mean age of air and transport in a CTM: Comparison of different ECMWF analyses. Geophys. Res. Lett., 34, L04801, doi:10.1029/ 2006 GL028515.

Nedelec, P., and Coauthors, 2003: An improved infrared carbon monoxide analyser for routine measurements aboard commercial aircraft: Technical validation and first scientific results of the MOZAIC III programme. Atmos. Chem. Phys., 3, 1551-1564.

Rabier, F., H. Järvinen, E. Klinker, J.-F. Mahfouf, and A. Simmons, 2000: The ECMWF operational implementation of four dimensional variational assimilation. Part I: Experimental results with simplified physics. Quart. J. Roy. Meteor. Soc., 126, 1143-1170.

Roberts, G., M. J. Wooster, G. L. W. Perry, N. Drake, L.-M. Rebelo, and F. Dipotso, 2005: Retrieval of biomass combustion rates and totals from fire radiative power observations: Application to southern Africa using geostationary SEVIRI imagery. J. Geophys. Res., 110, D21111, doi:10.1029/2005JD006018.

Stajner, I., L.-P. Riishoejgaard, and R. B. Rood, 2001: The GEOS ozone data assimilation system: Specification of error statistics. Quart. J. Roy. Meteor. Soc., 127, 1069-1094.

van der Werf, G. R., J. T. Randerson, L. Giglio, G. J. Collatz, and P. S. Kasibhatla, 2006: Interannual variability in global biomass burning emission from 1997 to 2004. Atmos. Chem. Phys., 6, 3423-3441.

Vermote, E. F., D. Tanre, J.-L. Deuze, M. Herman, and J.-J. Morcrette, 1997: Second simulation of the satellite signal in the solar spectrum, $6 \mathrm{~S}$ : an overview. IEEE Trans. Geosci. Rem. Sens., 35 (3), 675-686.

Wooster, M. J., B. Zhukov, and D. Oerlet, 2003: Fire radiative energy for quantitative study of biomass burning: Derivation from the BIRD experimental satellite and comparison to MODIS fire products. Remote Sens. Environ., 86, 83-107. 